\title{
Pengembangan Angkutan Umum Terintegrasi di Kota Surakarta
}

\author{
Development of Integrated Public Transportation in Surakarta City
}

\author{
Anandhika Arifianto ${ }^{\text {* }}$ \\ ${ }^{a}$ Sekolah Arsitektur,Perencanaan dan Pengembangan Kebijakan, Institut Teknologi Bandung, Bandung, Indonesia
}

\begin{abstract}
Abstrak
Pengembangan angkutan umum dalam langkah utama mengurai kemacetan lalu lintas di Kota Surakarta. Disediakan berbagai alternatif angkutan umum yang mulai terintegrasi secara langsung, seperti Batik Solo Trans (BST), angkutan kota, bus tingkat werkudara, dan railbus. Berbanding lurus dengan banyaknya alat transportasi umum akan berdampak besar kepada terurainya kemacetan lalu lintas yang telah terjadi. Telah banyak masyarakat di Kota Surakarta yang memanfaatkan angkutan umum umum yang terintegrasi dan berkelanjutan.
\end{abstract}

Kata kunci: Integrasi, Angkutan Umum, Berkelanjutan

\begin{abstract}
Development of public transportation in the main steps to unravel traffic congestion in Surakarta City. Various alternative public transports are provided which are directly integrated, such as Batik Solo Trans (BST), city transportation, Werkudara-level buses, and railbus. Directly proportional to the number of public transportation equipment will have a major impact on the breakdown of traffic congestion that has occurred. There have been many people in Surakarta City who utilize integrated and sustainable public public transportation.
\end{abstract}

Keyword: Integration, Public Transport, Sustainable

\section{Pendahuluan}

Berpindah adalah beralih (beranjak dan sebagainya) ke tempat lain; bertukar atau berganti (tempat, kedudukan, kantor, dan sebagainya) (KBBI, 2007). Semua umat manusia dalam beraktivitas akan melakukan perpindahan, baik melewati darat, laut, maupun udara. Melalui pergerakan yang menuntut manusia untuk berpindah, maka hadirlah alat-alat transportasi yang semakin memudahkan manusia dalam melakukan perpindahan. Kebutuhan akan adanya alat transportasi merupakan kebutuhan kelancaran, kenyamanan, dan keamanan yang tidak dapat dipisahkan dari kehidupan manusia modern guna meningkatkan produktivitas.

Pada dasarnya masyarakat akan melakukan perpindahan dengan tujuan yang berbeda sehingga diperlukan transportasi yang memudahkan dalam berpindah sesuai dengan tujuannya masing-masing. Perpindahan yang dilakukan masyarakat perlu didukung dengan adanya angkutan pribadi dan angkutan umum. Kemajuan teknologi berdampak terhadap perkembangan transportasi yang kini meningkat kualitas dan kuantitas daya angkutnya. Semakin banyaknya angkutan pribadi akan menimbulkan masalah baru, yaitu kemacetan. Oleh karena itu perlu dikembangkan angkutan umum yang terintregrasi sehingga tercapainya tujuan perpindahan setiap masyarakat.

\footnotetext{
* Corresponding author. Anandhika Arifianto.

E-mail address: anandhika56@gmail.com.
} 
Tujuan dari penulisan jurnal ini adalah untuk mengetahui bagaimana pengembangan angkutan umum terintegerasi di Kota Surakarta sehingga dapat dicontoh dan dikembangkan oleh Kota/Kabupaten lainnya. Jurnal ini diharapkan dapat mengidentifikasi masalah sehingga didapat solusi dari pengembangan angkutan umum terintegerasi di Kota Surakarta yang nantinya dapat dimanfaatkan atau digunakan dalam mengambil keputusan atau kebijakankebijakan, digunakan sebagai sumber informasi dan referensi dalam pengembangan angkutan umum terintegerasi di Indonesia.

\section{Metode}

Pada penelitian ini digunakan metode studi literatur dari berbagai sumber, dan menggunakan pengumpulan data melalui kuisioner online. Dimana melalui kuisioner online diperoleh data dari 100 responden sebagai berikut.

Tabel 1 Data Kuisioner Online Terhadap Masyarakat Kota Surakarta (Penulis,2017)

\begin{tabular}{clc}
\hline No & Aspek & $\begin{array}{c}\text { Prosentasi responden } \\
\text { menjawab "ya" }\end{array}$ \\
\hline 1 & Angkutan umum di Kota Surakarta sudah terintegerasi & $73 \%$ \\
2 & $\begin{array}{l}\text { Puas akan pelayanan angkutan umum di Kota Surakarta } \\
3\end{array}$ & $\begin{array}{l}\text { Adanya upaya pemerintah kota dalam mewujudkan } \\
\text { angkutan umum terintegerasi }\end{array}$
\end{tabular}

Kota Surakarta telah mengembangkan angkutan umum terintegrasi, agar kedepannya tidak timbul masalah kemacetan, ekonomi, dan sosial yang semakin parah. Pengembangan angkutan umum di Kota Surakarta sudah mulai terintegrasi satu sama lain, seperti halnya Batik Solo Trans (BST), kereta api, railbus, dan pesawat. Kesepuluh kali berturut-turut pada tahun 2006-2016 piala Wahana Tata Nugraha (WTN) diberikan kepada Kota Surakarta. Oleh karena itu, Kota Surakarta sebagai kota budaya memiliki track record dalam bidang angkutan kota yang terintegrasi.

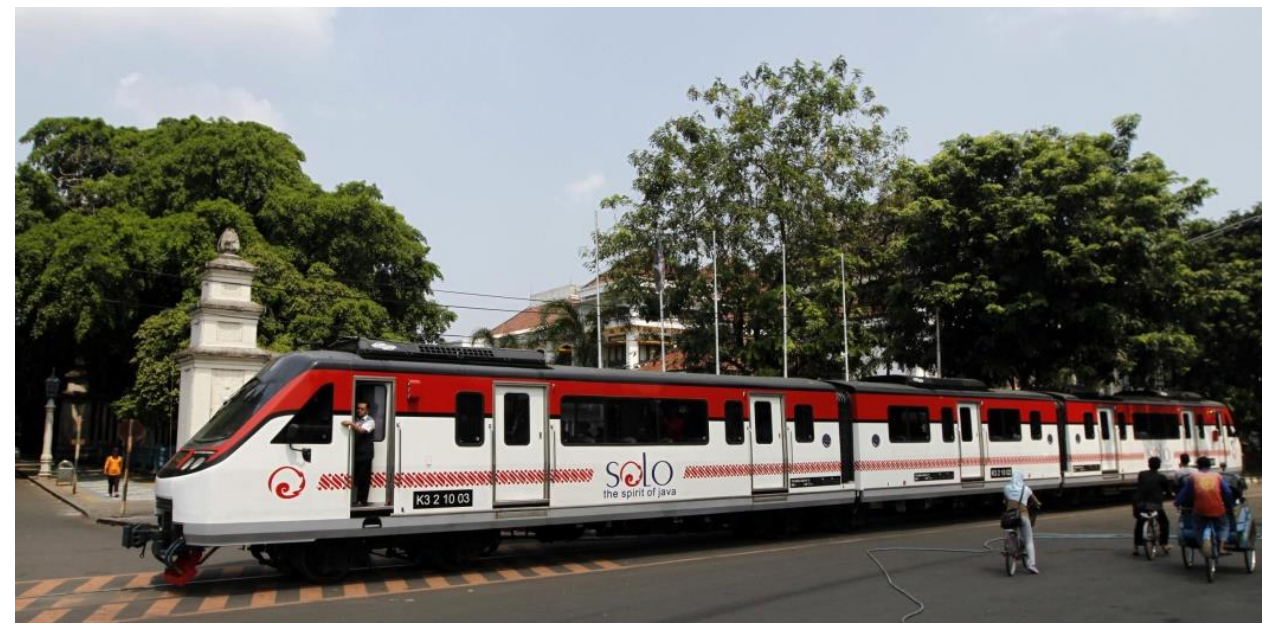

Gambar 1. Railbus Batara Kresna (harianjogja.com, 2017)

Penghargaan Wahana Tata Nugraha (WTN) merupakan merupakan penghargaan kepada pemerintah daerah yang mampu menata dan meningkatkan kinerja sistem transportasi perkotaan sehingga tercipta lalu lintas dan angkutan kota yang tertib, lancar, selamat, aman, efisien, berkelanjutan dan menjamin kesetaraan ungkap Hady Rudiatmo dalam Budi, (2017). Angkutan umum di Kota Surakarta, memang tidak hanya didesain agar saling terintegrasi, namun juga efisien, berkelanjutan, nyaman, dan aman. Banyak pilihan alternatif angkutan umum yang ditawarkan, mulai dari bus kota, kereta, railbus, becak, dan lainnya. Antar angkutan umum sudah terintegrasi sehingga memudahkan masyarakat dalam melakukan perpindahan. 


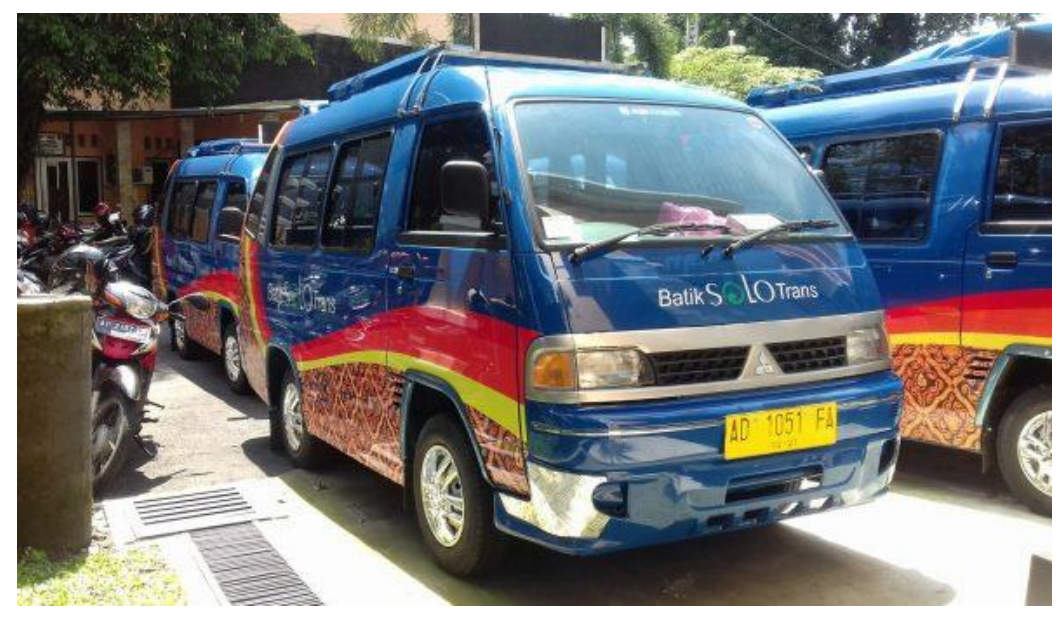

Gambar 2 Angkutan kota (feeder) (timlo.net, 2017)

Berdasarkan studi literatur dari pidato pengukuhan jabatan guru besar yang ditulis oleh Munawar (2007) diperoleh bahwa integrasi antar moda dapat berupa keterpaduan fisik, yaitu titik simpul pertemuan antar moda terletak dalam satu bangunan, misalnya bandara, terminal bus dan stasiun kereta api merupakan satu bangunan atau terletak berdekatan atau keterpaduan sistem, yaitu titik simpul dari masing-masing moda tidak perlu pada satu bangunan, tetapi ada suatu sitem jaringan transportasi yang menghubungkan titik simpul antar moda sehingga merupakan satu kesatuan yang utuh. Keterpaduan secara sistem juga menyangkut jadual keberangkatan, pelayanan pembelian karcis serta pengelolaannya (Ortúzar \& Willumsen, 1994). Dengan keterpaduan tersebut, akan memudahkan perjalanan, walaupun harus berganti moda sampai beberapa kali. Keterpaduan antar moda juga akan meningkatkan penggunaan angkutan umum.

\section{Angkutan Umum Terintegrasi Batik Solo Trans dan Kereta Bandara}

Integrasi moda angkutan umum memudahkan masyarakat dalam melakukan perpindahan. Bus perkotaan tidak hanya mengantarkan masyarakat ke tujuan masing-masing, tetapi juga mengintegrasikan antar angkutan umum. Bus perkotaan di Kota Surakarta atau lebih dikenal dengan Batik Solo Trans (BST) menghubungkan Stasiun Solobalapan di Surakarta, Stasiun Purwosari di Surakarta, terminal Tirtonadi di Surakarta, bandara Adi Soemarmo di Boyolali, terminal Palur di Karanganyar, di terminal Kartosuro di Sukoharjo. Maka dengan terkoneksinya angkutan umum dapat meningkatkan mobilitas masyarakat Surakarta dan sekitarnya. Jumlah penumpang Bus Batik Solo Trans (BST) yang beroperasi di koridor 1 (Bandara-Terminal Palur) dan koridor 2 (Terminal Kartasura-Terminal Palur) mencapai 10.000 orang/hari, Dinas Perhubungan Kota Surakarta (2017).

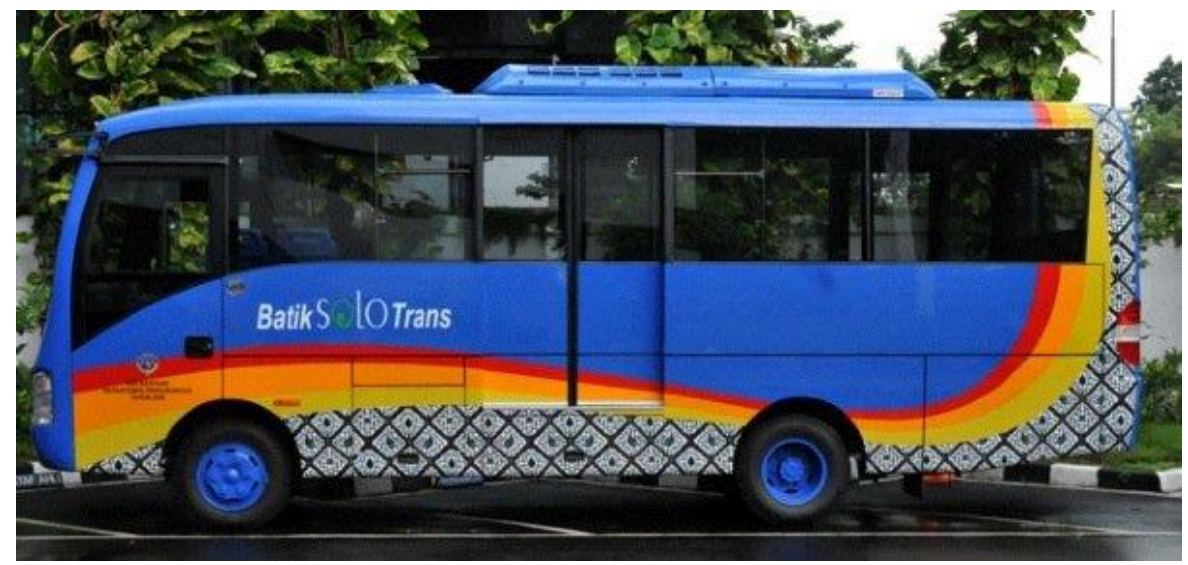

Gambar 3 Bus Batik Solo Trans berukuran sedang (tentangsolo.web.id, 2017) 
Terdapat delapan koridor BST dengan 159 armada dan angkutan kota sebanyak 380 armada di tahun 2015 yang melayani masyarakat (Badan Pusat Statistik, 2016). Dengan jumlah tersebut dapat memenuhi permintaan kebutuhan angkutan umum yang nyaman dan saling terhubung. Delapan koridor BST dapat menghubungkan lokasi-lokasi penting di Kota Surakarta, seperti balaikota Surakarta, pasar Gede, rumah sakit Kasih Ibu, rumah sakit Panti Waluyo, rumah sakit PKU Muhammadiyah, Solo Paragon Lifestyle Mall, Solo Grand Mall, Solo Square Mall, Pusat Grosir Solo, dan lokasi penting lainnya. Dengan tarif yang terjangkau dibandingkan dengan meggunakan kendaraan pribadi, membuat BST menjadi alternatif angkutan umum masyarakat di kota Surakarta.

Pembangunan kereta bandara yang akan menghubungkan Stasiun Solobalapan di Surakarta dengan bandara Adi Soemarmo di Boyolali merupakan salah satu upaya pengadaan angkutan umum pengintegrasi yang berbasis pada rel. Dengan dibangunnya kereta bandara ini, penumpang kereta yang akan melanjutkan perjalanannya menggunakan pesawat atau sebaliknya dapat lebih efektif dalam berpindah angkutan umum masal.

\section{Sarana dan Prasaran Penunjang Angkutan Umum Terintegrasi}

Pengadaan angkutan umum yang terintegrasi antar angkutan umum memerlukan sarana dan prasarana penunjang. Sarana dan prasarana penunjang dipersiapkan sebelum dioperasikannya angkutan umum tertentu. Dengan adanya sarana dan prasarana penunjang maka akan memberikan rasa lebih nyaman kepada pengguna angkutan umum sehingga pengguna angkutan umum tidak merasa kapok dan terus menggunakan angkutan umum masal. Tidak hanya mendukung dalam memaksimalkan pengoperasian angkutan umum, sarana dan prasarana penunjang angkutaan umum dapat menjadi pengintegrasi antar angkutan umum sehingga tidak memerlukan angkutan umum pengintegrasi.

Persepsi penumpang menunjukkan kurangnya mutu pelayanan dan belum sesuai dengan apa yang diinginkan/diperkirakan. Karena dipengaruhi oleh kualitas dari sarana, prasarana dan pengoperasian fasilitas angkutan umum itu sendiri, (Soegoto, 2011). Meningkatkan fasilitas berupa sarana dan prasarana pendukung dapat mengubah persepsi masyakarkat tentang ketidak nyamanan menggunakan angkutan umum, dan Kota Surakarta sudah menerapkannya. Sarana dan prasarana pendukung juga menghubungkan antar angkutan umum, seperti sky bridge yang menghubungkan Stasiun Solobalapan dengan Terminal Tirtonadi. Dengan adanya sky bridge dapat mempermudah pengguna kereta api yang akan melanjutkan perjalanannya menggunakan bus dan sebaliknya, tanpa harus mengeluarkan uang lagi untuk menggunakan taksi atau becak.

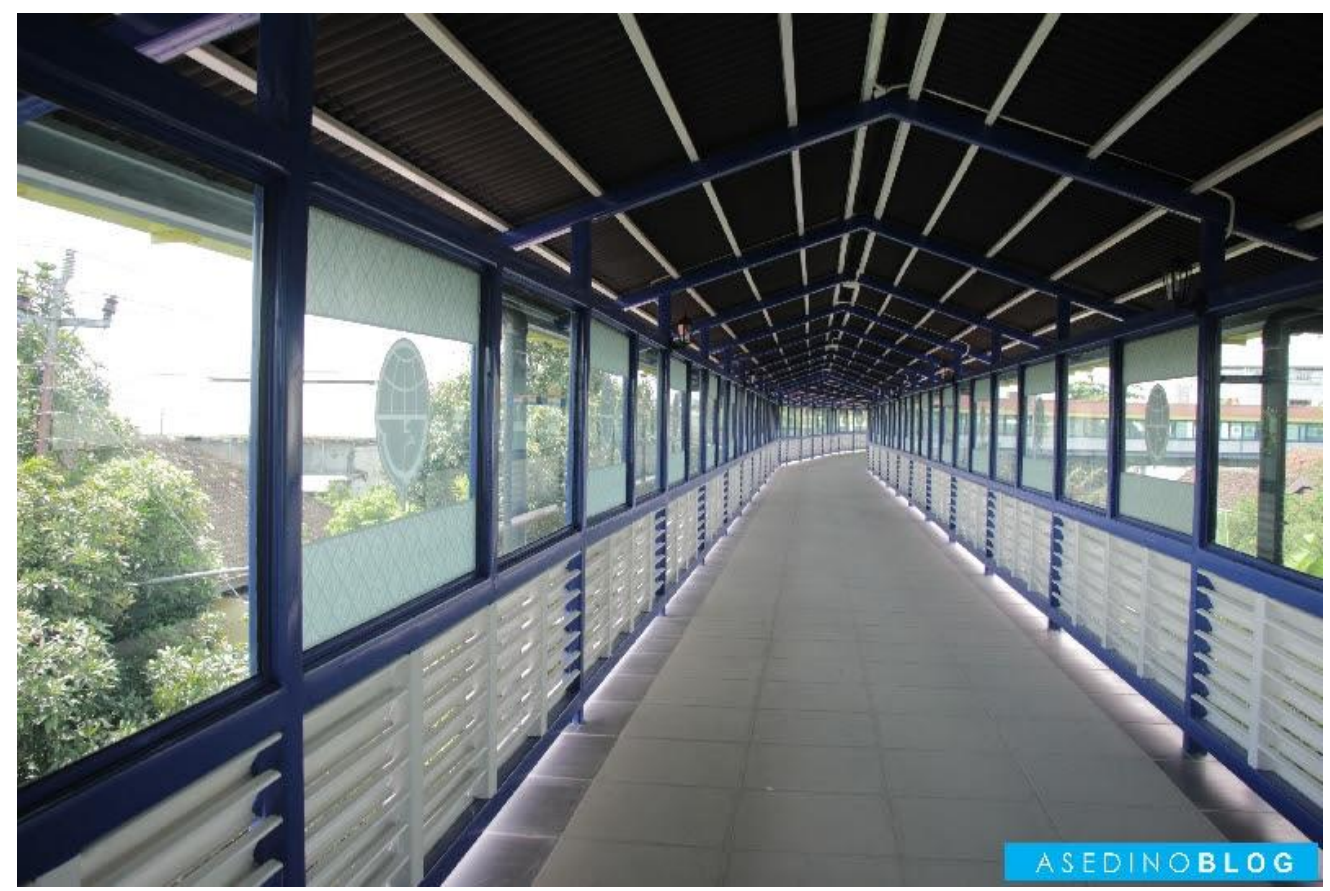

Gambar 4 Skybridge stasiun Solobalapan ke terminal Tirtonadi (asedino.wordpress.com, 2017) 
Peggunaan aplikasi Moovit dalam mengecek rute dan memantau pergerakan armada BST, sekaligus mengetahui waktu tunggu kedatangan bus di titik pemberhentian. Aplikasi yang berbasis android dapat mendukung operasional BST dan dikembangkan pada semua koridor BST serta angkutan 'feeder' (Sudjatmiko, 2017) sehingga koneksitas antar angkutan umum umum dapat berjalan lebih efektif. Maka sarana ini dapat mempermudah calon pengguna dalam menggunakan angkutan umum BST.

\section{Dampak Menggunakan Angkutan Umum Terintegrasi}

Guna mewujudkan perencanaan angkutan umum yang merupakan satu kesatuan dalam lingkup nasional maupun regional, Pemerintah Pusat, dalam hal ini Departemen Perhubungan, telah membuat konsep perencanaan transportasi yang disebut dengan Tataran Transportasi, (Menteri Perhubungan Republik Indonesia, 2005). Oleh sebab itu, dalam perencanaan transportasi sudah diatur dalam Tratanan Transportasi di tingkat nasional, provinsi, dan kabupaten/kota. Dengan demikian dapat menciptakan tatanan transportasi yang teratur dan berkelanjutan. Berkelanjutan dalam artian bahwa angkutan umum dapat digunakan tidak hanya pada masa sekarang saja, karena seiring dengan perkembangan ilmu teknologi transportasi maka tercipta alat-alat transportasi yang ramah lingkungan dan berkelanjutan.

Berdasarkan The Centre of Sustainable Transportation Canada (2002), Sistem transportasi yang berkelanjutan adalah sistem transportasi yang (1) Menjadi akses utama dibutuhkan oleh individu dan masyarakat agar keamanannya lebih terjaga, manusiawi, tidak mencemari lingkungan, dan memberikan keadilan baik di dalam maupun antargenerasi; (2) Dapat dioperasikan secara efisien, memberikan pilihan angkutan umum dan mendukung pergerakan aspek ekonomi; (3) Membatasi emisi, pemborosan dalam kemampuan bumi menyerapnya, meminimalkan penggunaan sumber daya alam yang tidak dapat diperbarui, membatasi penggunaan sumber daya alam yang dapat diperbarui agar kualitasnya tetap terjaga, menggunakan dan memperbarui bagian-bagiannya, dan meminimalkan penggunaan lahan dan produksi yang menimbulkan kegaduhan.

Banyak dampak apabila menggunakan angkutan umum Batik Solo Trans, diantaranya dapat menghemat biaya transportasi, mengurangi kemacetan lalu lintas, menambah waktu bersosialisai dengan pengguna BST lain, mensukseskan program pemerintah dalam bidang transportasi, dan secara tidak langsung mengurangi polusi udara akibat gas buangan kendaraan bermotor (Wahluya, 2016). Selain itu menggunakan angkutan umum dapat mengurangi konsumsi bahan bakar yang berdampak pada penciptaan langit bersih. Menggunakan angkutan umum BST juga lebih aman dan nyaman, karena dapat megurangi resiko kecelakaan berlalu lintas dan fasilitas pendukung yang tidak didapatkan jika menggunakan sepeda motor pribadi.

Dari segi perekonomian kota mnggunakan angkutan umum dapat meningkatkan aksesibilitas bagi kaum miskin untuk melakukan mobilitas sehingga dapat menjadi lebih murah. Sistem transportasi yang sekarang telah membuat golongan miskin mengeluarkan $20 \%-40 \%$ pendapatan untuk transportasi, (Aminah, 2017)

\section{Simpulan}

Kota Surakarta dapat menjadi percontohan dalam hal mengelola angkutan umum yang terintegrasi dan berkelanjutan. Banyak alternatif angkutan umum yang dapat dipilih untuk melakukan perpindahan menuju ke suatu tempat. Tersedia angkutan umum, seperti Batik Solo Trans dan angkutan kota dengan rute yang melewati tempat-tempat penting di Kota Surakarta. Peningkatan sarana dan prasarana pendukung terus ditingkatkan oleh pemerintah kota demi mewujudkan kenyamanan dan keamanan dalam menggunakan transportasi umum. Dengan demikian semakin banyak masyarakat yang mulai berpindah dari menggunakan angkutan pribadi menjadi menggunakan angkutan umum.

Pada kenyataannya lebih menguntungkan menggunakan angkutan umum umum daripada menggunakan angkutan pribadi. Hal ini dikarenakan banyaknya manfaat yang didapatkan dari menggunakan angkutan umum, seperti menghemat biaya transportasi, mengurangi kemacetan lalu lintas, menambah waktu bersosialisai dengan pengguna BST lain, 
mensukseskan program pemerintah dalam bidang transportasi. Akibatnya, banyak masyarakat di Kota Surakarta yang telah menggunakan angkutan umum dalam melakukan perpindahan ke tujuan tertentu.

\section{Referensi}

Aminah, S. (2017). Transportasi Publik dan Aksesibilitas Masyarakat Perkotaan. Masyarakat, Kebudayaan Dan Politik, 4(1), 31-45.

Badan Pusat Statistik. (2016). Kota Surakarta Dalam Angka 2016. Surakarta: BPS Kota Sukarta.

Budi, M. (2017). Solo Raih Penghargaan Wahana Tata Nugraha ke 10 kali. Retrieved February 20, 2017, from detiknews website: https://news.detik.com/berita/d-3410217/solo-raih-penghargaan-wahanatata-nugraha-ke-10-kali

Menteri Perhubungan Republik Indonesia. Peraturan Menteri Perhubungan No. KM. 49 Tahun 2005 Tentang Sistem Transportasi Nasional (SISTRANAS). , (2005).

Munawar, A. (2007). Pengembangan Transportasi yang Berkelanjutan. Yogyakarta.

Ortúzar, J. de D., \& Willumsen, L. G. (1994). Modelling Transport. England: John Wiley \& Sons, Inc.

Soegoto, D. S. (2011). Peningkatan Prasarana, Sarana, Sistem Operasi Pelayanan Jasa Angkutan Umum Bis Kota Damri Berdasarkan Ekspektasi dan Persepsi Penumpang. Majalah Ilmiah Unikom, 8(2), 217-230.

Sudjatmiko, T. (2017). Pangkas Waktu BST, Dishub Uji Coba Aplikasi Moovit. Retrieved January 28, 2017, from krjogja.com website: https://krjogja.com/web/news/read/25203/Pangkas_Waktu_BST_Dishub_Uji_Coba_Aplikasi_Moo vit

Wahluya, N. (2016). 6 Manfaat Menggunakan Transportasi Umum. Retrieved February 20, 2017, from Inspirasi website: https://student.cnnindonesia.com/inspirasi/20160810161053-454-150493/6manfaat-besar-menggunakan-transportasi-umum 